\title{
PEG- INDUCED DROUGHT STRESS EFFECTS ON SPINACH GERMINATION PARAMETERS
}

\author{
${ }^{1}$ TAHOORA BATOOL ZARGAR, ${ }^{1}$ FAIZA ASHRAF, ${ }^{1,2}$ SZILVIA VERES* \\ ${ }^{1}$ University of Debrecen \\ Faculty of Agricultural and Food Sciences and Environmental Management \\ Institute of Crop Sciences \\ Department of Applied Plant Biology
}

*Corresponding author : szveres@agr.unideb.hu

\begin{abstract}
Exposure to the drought stress reduces germination rate and seedling's growth with significant variations from crop to crop. An unavoidable consequence of drought exposure is the generation of reactive oxygen species. They can be extremely reactive with several cellular constituents such as proteins, lipids, and nucleic acids. Spinach (Spinacia oleracea L.) is one of the most consumed vegetable species, rich in vitamins, such as vitamin $\mathrm{C}$, and minerals, which are essential for human health. Besides, spinach contains large amounts of bioactive molecules such as glucuronic acid derivatives of flavonoids and p-coumaric acid derivatives that exhibit strong antioxidant activity Osmotic solutions of polyethylene glycol (PEG) are commonly used to control water potential in seed germination studies. PEG reduces the water potential of osmotic solutions but may limit oxygen availability to germinating seeds. The purpose of this study was to determine whether seed immersion in PEG solution had a detrimental effect on total Germination percentage, Relativized percentage, Mean germination time, Mean germination rate, Coefficient of variation of germination time, Coefficient of the velocity of germination, Germination index, Uncertainty of germination process, Synchronization index, Time to $10 \%$ germination, Time to $25 \%$ germination, Time to $50 \%$ germination, Time to $75 \%$ germination, Time to $90 \%$ germination, Time from 10 to $90 \%$ germination, Time from 25 to $75 \%$ germination, Mean daily germination Percent, Peak value for germination, Germination value. A controlled experiment was conducted to investigate the effects of drought stress, induced by PEG, on these germination parameters in Spinach. For control, seeds were treated with nutrient solution, and 2.5\% PEG was used to induce drought stress. The seeds were germinated geotropically between moisten filter papers. Each roll contained 30 seeds. Overall germination parameters showed a decrease as compared to control. The germination percentage of control seeds of Spinach oleracea L. was $79 \%$ while those treated with PEG were only $63 \%$. Similarly, the relativized percentage decrease was observed in the case of PEG-treated seeds. Relativized percentage of control seeds was $91 \%$ as treated seeds were only $73 \%$. Both showed a significant decrease as compared to the control.
\end{abstract}

Keywords: : Drought stress, Germination, Spinach, PEG

\section{INTRODUCTION}

Spinach (Spinacia oleracea L.), associated to family Chenopodiaceae, is one of the most famous green leafy vegetable crops with minimum growth cycle and is an annual plant (Biemond et al., 1996). Spinach is highly nutritious due to presence of minerals and vitamins. It is a good source of calcium, vitamin C, phosphorous, iron, potassium and sodium (Dicoteau, 2000, Morelock, T.E. and Correll, J.C., 2008). It originated from central Asia, probably from Persia. 31,770 ha are dedicated to its cultivation in the countries that are from the European Union. Spinach covers about 5100 ha and annual production is about 86,990 tons in Spain. It was introduced to Spain by Arabs and subsequently finding its way into the rest of Europe according to Kaur et al., (2011) in the book Origin of Cultivated Plants (Murcia et al.,). Changing climate and lack of proper irrigation is 
enhancing drought conditions which creates hindrance in the cultivation of crops (Anjum et al., 2011). The crucial phase in the life cycle of plants is seed germination, which determines the successful establishment of seedlings and subsequent growth. In the initial stage, plants are more sensitive to environmental stresses than other growth and developmental stages (M'barek et.al (2007), Luan, Z.et.al. (2014). Abiotic stresses like drought, heat, heavy metal and light have a significant effect on seed germination and related parameters (Bhattacharya, et al., 2012). In extreme cases these factors may lead to injury and death of the plant. One of the major constraints impairing crop growth around the globe is drought stress. The first stage of germination is the absorption of water. Seeds, whether dead or alive, absorb water and swell and the quantity of absorbance depends on the chemical composition of seeds. Germination declines or stops if the water level is less than desirable as the main factor of stimulating germination is water and access to water by osmotic and matric potential (suction) is reduced (Baskin, C. C., et al., 1998). Rate of water absorption depends on the water potential of environment. Drought can reduce the germination rate but sensitivity towards drought stress differs at different stages of germination (Ahmad, S.et.al. 2009).With increasing severity of the drought, the percentage and rate of germination, germination index was reduced in several species (Alqudah, et al., 2011). Drought stress affects many aspects of plant growth delay in germination, reduction in the growth of shoot and reduce the production of dry matter (Shekari, 2000). Drought stress not only decreases overall plant growth, but also leads the cultivatable land into barren non-cultivatable area. This reduction in the crop yield is mainly attributed to a disturbance in the biochemical and physiological processes under drought condition (Hoekstra et al., 2001). It is believed that due to accumulation of higher amount of ethylene in plants facing drought stress, the yield is reduced. Ethylene plays an important role in evoking the physiological responses under drought stress (Wang et al., 2003). So, the current study was conducted with the aim to explore the effect of PEGinduced drought stress on the various germination parameters of Spinach seeds. It is hypothesized that the PEG will lead to decrease in the germination rate and germination index as compared to control, but differences are expected in terms of sensitivity of parameters to drought.

\section{MATERIAL AND METHODS}

Spinach Seeds (Spinacia oleracea var. Matador), taken from Garafarm trade Kft. Budapest were surface sterilized using $6 \%[\mathrm{v} / \mathrm{v}] \mathrm{H}_{2} \mathrm{O}_{2}$ for 20 minutes, after that washed and rinsed extensively with deionized water. The treatment of $2.5 \%$ concentration PEG 6000 [VWR international bvba Geldenaaksebaan, Leuven, Belgium] solution was applied to the seeds in three replicates, and for control treatment, the nutrient solution was applied. The nutrient solution consisted of the following substances: $2.0 \mathrm{mM} \mathrm{Ca}\left(\mathrm{NO}_{3}\right)_{2}, 0.7 \mathrm{mM} \mathrm{K} \mathrm{SO}_{4}$, $0.5 \mathrm{mM} \mathrm{MgSO}_{4}, 0.1 \mathrm{mM} \mathrm{KH}_{2} \mathrm{PO}_{4}, 0.1 \mathrm{mM} \mathrm{KCl}, 10 \mu \mathrm{M} \mathrm{H}_{3} \mathrm{BO}_{3}, 0.5 \mu \mathrm{M} \mathrm{MnSO}_{4}, 0.5 \mu \mathrm{M}$ $\mathrm{ZnSO}_{4}$ and $0.2 \mu \mathrm{M} \mathrm{CuSO}_{4}$. Iron was supplied in the form of $10^{-4} \mathrm{M}$ Fe-EDTA too (Cakmak and Marschner 1990). The seeds were germinated geotropically between moisten filter papers at $24{ }^{\circ} \mathrm{C}$. Each roll contained 30 seeds. Seed germination was counted every day, and the daily associated root elongation was measured with ruler. From the germination counts, the following germination parameters were determined after 7 days of sowing: 
Germination percentage:

$$
G(\%)=\frac{\sum_{i=1}^{h} n_{i}}{N} \times 100
$$

Relativized percentage:

$$
\begin{array}{r}
R(\%)=\frac{A P}{H P} \times 100 \\
\bar{t}=\frac{\sum_{i=1}^{k} n_{i} t_{i}}{\sum_{i=\Perp}^{k} n_{i}}
\end{array}
$$

(Fitch et al. 2007)

Mean germination time:

(Ellis and Roberts

1981)

Mean germination rate:

$$
\bar{v}=\frac{1}{\bar{t}}
$$

Uncertainty of germination process:

$U=\sum_{i=1}^{k} f_{i} \log _{2} f_{i}$ (Labouriau and Valadares 1976)

Where; $f_{i}=\frac{n_{i}}{\Sigma_{i=\Perp}^{k} n_{i}} f_{i}=$ Relative frequency of germination

Synchrony of germination process: $\quad Z=\frac{\sum_{i=1}^{k} c_{n_{i}, 2}}{c_{\Sigma} n_{i} \mu^{2}} \quad$ (Labouriau 1978)

Coefficient of variation of germination time: $C V_{t}=\frac{S_{t}}{t} \times 100$ (Ranal et al. 2009

Germination index:

$G I=\sum_{i=1}^{k} n_{i} / t_{i}$ (AOSA and SCST 1993

Coefficient of velocity of germination:

$C V G=\frac{\sum_{i=1}^{k} n_{i} t_{i}}{\sum_{i=1}^{k} n_{i}} \times 100$ (Jones and Sanders 1987)

Time to $50 \%$ germination: $\quad T_{\mathrm{E}: 0}=\frac{t_{i}+\left(\frac{\sum_{i=1}^{k} n_{i}}{2}-n_{i}\right)\left(t_{j}-t_{i}\right)}{n_{j}-n_{i}}$ (Coolbear, Francis, and Grierson 1984)

In the above equation to find out the value of ni and nj there is need to look in the cumulative number of seeds germinated for which the condition is given below.

$$
n_{i}<\frac{\sum_{i=1}^{k} n_{i}}{2}<n_{j}
$$

Where; ni= nearest cumulative number of seeds germinated $\left(C_{n_{i}}\right)<\frac{\sum_{i=1}^{k} n_{i}}{2}$

$\mathrm{nj}=$ nearest cumulative number of seeds germinated $\left(C_{n_{i}}\right)>\frac{\sum_{i=1}^{k_{t}} n_{i}}{2}$

$\mathrm{t} i=$ the time interval corresponding to $\mathrm{ni}$

$\mathrm{t} \mathrm{j}=$ the time interval corresponding to $\mathrm{nj}$

Other time related germination parameters like T10, T25, T75 and T90 were calculated

using the same above formula by replacing $\frac{\sum_{i=1}^{k} n_{i}}{2}$ with $\frac{\sum_{i=1}^{k} n_{i}}{10}, \frac{\sum_{i=1}^{k} n_{i}}{4}, \frac{3 \sum_{i=1}^{k} n_{i}}{4}$ and $\frac{9 \sum_{i=1}^{k} n_{i}}{10}$ respectively.

Mean daily germination percent:

$$
\bar{G}=\frac{G P}{T_{\pi}} \quad \text { (Adams and Farrish 1992) }
$$

Germination value: By combining both speed and completeness of germination into a composite score as described by Czabator (1962).

$$
\mathrm{GV}=\mathrm{MDG} \times \mathrm{PV}
$$

Experimental design and statistical analysis: Treatments were arranged in a completely randomized design with 3 replications and 30 seeds per replicate. For statistical analysis SigmaPlot 12 for Windows (Systat Software) was used. During the data analysis, t test was used.

\section{RESULTS}


Severe effect of drought was observed on various germination parameters. Significant decrease of $20 \%$ in germination percentage was recorded in PEG treated seeds in comparison to control. Similar to germination percentage, relativized percentage also decreased by $19.75 \%$ under drought condition (Table.1).

Mean germination time decreased by $27.1 \%$ in PEG treated seeds in comparison to control. However, mean germination rate of control was less as compared to PEG treatment, 0.26 day $^{-1}$ in case of control and 0.35 day $^{-1}$ in PEG treated seeds. Decrease of $18.14 \%$ in coefficient of variation of germination time compared with control was recorded (Table.1). Coefficient of velocity of germination was high $(28.37 \%)$ in PEG treated seeds than control (Table.1). Decrease in germination Index by 5.96\% was recorded in PEG treated seeds (Table.1).

Mean daily germination values also showed the significant decrease by $19.8 \%$ in PEG treated seeds. Decrease by $17.9 \%$ in germination value was recorded in drought condition. Time to $25 \%$ germination, Time to $50 \%$ germination, Time to $75 \%$ germination, Time to $90 \%$ germination, Time from 10 to $90 \%$ germination, Time from 25 to $75 \%$ germination also decreased in case of PEG treatment along the slight increase in peak value of germination as shown in table 1.

Table 1. Comparison between control and treatment among various parameters $[n=3 \pm S E]$ where $\mathrm{n}=$ no. of replications, $\mathrm{SE}=$ standard error.

\begin{tabular}{|l|l|l|l|}
\hline Germination Parameters & Units & \multicolumn{1}{|c|}{ Control } & \multicolumn{1}{|c|}{$\mathbf{2 . 5 \%}$ PEG } \\
\hline Germination percentage G\% & $\%$ & $79 \pm 4.93$ & $63 \pm 1.92$ \\
\hline Relativized percentage R\% & $\%$ & $91 \pm 5.50$ & $73.07 \pm 2.24$ \\
\hline Mean germination time MGT & day $^{-1}$ & $3.91 \pm 0.45$ & $2.85 \pm 0.29$ \\
\hline Mean germination rate MGR & day $^{-1}$ & $0.26 \pm 0.03$ & $0.35 \pm 0.03$ \\
\hline Coefficient of variation of germination time CVt & $\%$ & $52.07 \pm 6.63$ & $42.61 \pm 5.41$ \\
\hline Coefficient of velocity of germination CVg & $\%$ & $26.28 \pm 3.16$ & $35.69 \pm 3.34$ \\
\hline Germination index GI & day ${ }^{-1}$ & $9.06 \pm 2.23$ & $8.52 \pm 1.21$ \\
\hline Uncertainty of germination process U & bit & $2.37 \pm 0.16$ & $1.97 \pm 0.12$ \\
\hline Synchronization index Z & & $0.20 \pm 0.03$ & $0.26 \pm 0.03$ \\
\hline Time to 10\% germination & day & $0.916 \pm 0.458$ & $0.466 \pm 0.466$ \\
\hline Time to 25\% germination & day & $1.402 \pm 0.713$ & $1.216 \pm 0.656$ \\
\hline Time to 50\% germination & day & $3.437 \pm 0.598$ & $2.269 \pm 0.321$ \\
\hline Time to 75\% germination & day & $5.027 \pm 0.701$ & $5.027 \pm 0.701$ \\
\hline Time to 90\% germination & day & $6.222 \pm 0.308$ & $3.922 \pm 0.067$ \\
\hline Time from 10 to $90 \%$ germination & day & $3.405 \pm 1.712$ & $0.833 \pm 0.833$ \\
\hline Time from 25 to 75\% germination & day & $2.236 \pm 1.311$ & $0.870 \pm 0.435$ \\
\hline Mean daily germination MDG & $\%$ & $11.269 \pm 0.691$ & $9.047 \pm 0.274$ \\
\hline Peak value for germination & day ${ }^{-1}$ & $16.666 \pm 5.091$ & $17.500 \pm 1.734$ \\
\hline Germination value & & $194.19 \pm 69.60$ & $159.26 \pm 20.20$ \\
\hline
\end{tabular}


Overall decrease in germination parameters was observed. Drought leads to decrease in water potential in germination medium and prevents water absorption needed for germination process to start (Almansouri, M., J.M. Kinet, 2001). These results are in agreement with those reported by Dahal et al. (1996), Zayed et al. (1998), Lopez et al. (2000), Almansouri et al. (2001) and by Zhu et al. (2006). PEG not only delayed the germination but also affected the final germination percentages. Our results are not in agreement with those reported by Bradford (1990) and Almansouri et al. (2001) who stated that moderate osmotic stresses only delayed germination while high stresses reduced the final germination percentages. PEG, which is a non-penetrating osmoticum, prevents water uptake by plant cells. Yadvi et al (2000) concluded that germination percentage was decreased as osmotic potential goes to negative under drought stress caused by (PEG6000) on 6 barely cultivars.

In seeds that are soaked in nutrient solution, their water content reaches a plateau and up to just before radicle emergence changes very little. When the water potential is reduced outside the seeds media, the rate of water uptake decreases and the onset of germination is delayed. The major reason for germination delay is the increase in the length of the lag phase between imbibition and radicle growth, since the increase in seeds water content proceeds slowly during this period. In nutrient solution, seeds are saturated $(100 \%)$ with nutrient solution and as a result radicle growth occurs rapidly, but at higher osmotic potential (more negative) seeds water content increases gradually (Bradford, K.J., 1986). According to Bradford (1990), at high osmotic potential the degree of seeds endosperm weakening which primarily controls the time of radicle emergence due to lowered seed water potential or pressure potential (turgor) is delayed.

In conclusion, in this study drought tolerance in early phase of seedling growth of spinach was investigated by evaluating growth and germination process under PEG-induced water stress. It was observed that water stress causes delay and also inhibition of germination process which could be due to various physicals and metabolic parameters, the absorption of water by the seed [imbibition] activates metabolic processes that subsequently lead to expansion of the embryo and the penetration of radicle through surrounding tissue. Enzymatic hydrolysis of protein, lipids and carbohydrates and transportation of metabolites is dependent on water availability (Nonogaki, H., Bassel, G. W., \& Bewley, J. D. 2010), which plays an important role during germination.

\section{ACKNOWLEDGEMENT}

Project no. TKP2020-IKA-04 has been implemented with the support provided from the National Research, Development and Innovation Fund of Hungary, financed under the2020-4.1.1-TKP2020 funding scheme.

\section{REFERENCES}

Adams, J.C., Farrish, K.W. (1992): "Seedcoat Removal Increases Speed and Completeness of Germination of Water Oak." Tree Planters' Notes-US Department of Agriculture, Forest Service (USA).

Ahmad, S., Ahmad, R., Ashraf, M.Y., Ashraf, M., Waraich, E.A. (2009): Sunflower (Helianthus annuus L.) response to drought stress at germination and seedling growth stages. Pak. J. Bot, 41(2), 647-654. 
Almansouri, M., Kinet, J.M. ,Lutts, S., (2001) Effect of salt and osmotic stresses on germination in durum wheat (Triticum durum Desf.). Plant and Soil, 231(2), pp.243254.

Alqudah, A. M., Samarah, N. H., \& Mullen, R. E. (2011). Drought stress effect on crop pollination, seed set, yield and quality. In Alternative farming systems, biotechnology, drought stress and ecological fertilisation (pp. 193-213). Springer, Dordrecht. DOI: 10.1007/978-94-007-0186-1_6

Anjum, S.A., Xie, X.Y., Wang, L.C., Saleem, M.F., Man, C. and Lei, W., 2011. Morphological, physiological and biochemical responses of plants to drought stress. African Journal of Agricultural Research, 6(9), pp.2026-2032. https://doi.org/10.5897/AJAR10.027

AOSA, and SCST. 1993. "Rules for Testing Seeds." Journal of Seed Technology 16: 1113.

Baskin, C.C., Baskin, J.M. (1998): Seeds: ecology, biogeography, and, evolution of dormancy and germination. Elsevier.

Bhattacharya, S., Puri, S., Jamwal, A., Sharma, S. (2012): Studies on seed germination and seedling growth in Kalmegh (Andrographis paniculata Wall. Ex Nees) under abiotic stress conditions. Int J Sci Environ Technol, 1(3), 197-204.

Biemond, H., Vos, J. and Struik, P.C. (1996): Effects of nitrogen on accumulation and partitioning of dry matter and nitrogen of vegetables. 3. Spinach. NJAS Wageningen Journal of life Sciences, 44(3), pp.227-239.

Bradford, K.J. (1986) Manipulation of seed water relations via osmotic priming to improve germination under stress. HortScience, 21(5).

Bradford, K.J. (1990): A water relations analysis of seed germination rates. Plant Physiology, 94(2), pp.840-849. https://www.jstor.org/stable/4273166

Cakmak, I., \& Marschner, H. (1990): Decrease in nitrate uptake and increase in proton release in zinc deficient cotton, sunflower and buckwheat plants. Plant and Soil, 129(2), 261-268.

Coolbear, P, Francis, A., Grierson, D. (1984): "The Effect of Low Temperature PreSowing Treatment on the Germination Performance and Membrane Integrity of Artificially Aged Tomato Seeds." Journal of Experimental Botany 35 (11): 1609-17. https://doi.org/10.1093/jxb/35.11.1609

Czabator, F. J. (1962): Germination value: an index combining speed and completeness of pine seed germination. Forest science, 8(4), 386396.https://doi.org/10.1093/forestscience/8.4.386

Dahal, P., Kim, N.S., Bradford, K.J. (1996). Respiration and germination rates of tomato seeds at suboptimal temperatures and reduced water potentials. J. Exp. Bot., 47: 941947. https://doi.org/10.1093/jxb/47.7.941

Dicoteau, D. R. (2000). Vegetable crops. New Jersey: Prentice Hall.

Ellis, RH, and EH Roberts. 1981. "The Quantification of Ageing and Survival in Orthodox Seeds." Seed Science and Technology 9: 373-409.

Fitch, E.A., Walck, J.L., SN Hidayati, 2007. "Temporal Fulfilment of the Light Requirement for Seed Germination: An Example of Its Use in Management of Rare Species." Seeds: Biology, Development and Ecology, 365.

Gaballah, M. S., Abou, B., Leila, H., El-Zeiny, A., \& Khalil, S. (2007). Estimating the performance of salt-stressed sesame plant treated with anti transpirants. Journal of Applied Sciences Research, 3(9), 811-817.

Hoekstra, F. A., Golovina, E. A., \& Buitink, J. (2001). Mechanisms of plant desiccation tolerance. Trends in plant science, 6(9), 431-438. https://doi.org/10.1016/S1360$\underline{1385(01) 02052-0}$ 
Jones, K.W., Sanders, D.C. (1987): "The Influence of Soaking Pepper Seed in Water or Potassium Salt Solutions on Germination at Three Temperatures." Journal of Seed Technology, 97-102. https://www.jstor.org/stable/23432941

Kaur P., Rai, D.R., Paul, S. (2011): Quality changes in fresh-cut spinach (Spinacia oleracea) under modified atmospheres with perforations. Journal of Food Quality 34 (1): 10-18. https://doi.org/10.1111/j.1745-4557.2010.00361.x

Labouriau, L.G., Valadares, M.E.B. (1976): "On the Germination of Seeds of Calotropis Procera (Ait.) Ait. f." Anais Da Academia Brasileira de Ciencias 48: 263-84.

Labouriau, L.G. (1978): On the frequency of isothermal germination in seeds of Dolichos biflorus L. Plant and Cell Physiology, 19(3), 507-512.

https://doi.org/10.1093/oxfordjournals.pcp.a075620

Lopez, M., Humara, J.M., Gasares, A., Majada, J. (2000): The effect of temperature and water stress on laboratory germination of Eucalyptus globules Labill. Seeds of different size. Ann. For. Sci., 57: 245-250. Michel, B.E. and M.R. Kaufmann, 1973. The osmotic potential of polyethylene glycol 6000. Plant Physiol., 51: 914-916. https://doi.org/10.1051/forest:2000115

Luan, Z., Xiao, M., Zhou, D., Zhang, H., Tian, Y., Wu, Y.,Song, Y. (2014): Effects of salinity, temperature, and polyethylene glycol on the seed germination of sunflower (Helianthus annuus L.). The Scientific World Journal, 2014.

M'barek, B. N., Raoudha, A., Leila, B. K. (2007): Relationship between peroxidase activity and salt tolerance during barley seed germination. Journal of Agronomy.

Morelock, T.E., Correll, J.C. (2008): Spinach. In Vegetables I (pp. 189-218). Springer, New York, NY. DOI: 10.1007/978-0-387-30443-4_6

Murcia, M. A., Jiménez-Monreal, A. M., Gonzalez, J.,Martínez-Tomé, M. (2020): Spinach. In Nutritional Composition and Antioxidant Properties of Fruits and Vegetables (pp. 181-195). Academic Press. https://doi.org/10.1016/B978-0-12-8127803.00011-8

Nonogaki, H., Bassel, G. W.,Bewley, J. D. (2010): Germination-still a mystery. Plant Science, 179(6), 574-581. https://doi.org/10.1016/j.plantsci.2010.02.010

Ranal, M.A., Santana, D.G.,Ferreira, W.R:, Mendes R.C. (2009): "Calculating Germination Measurements and Organizing Spreadsheets.” Brazilian Journal of Botany 32: 849-55. https://doi.org/10.1590/S0100-84042009000400022

Shekari, F., Khoii, F.R., Javanshir, A., Alyari, H., Shkiba, M.R. (2000): Effects of sodium chloride salinity on germination of rapeseed cultivars. Turkish Journal of Field Crops, 5(1), pp.21-28.

Wang, W., Vinocur, B.., Altman, A. (2003): Plant responses to drought, salinity and extreme temperatures: towards genetic engineering for stress tolerance. Planta, 218(1), pp.1-14. https://doi.org/10.1007/s00425-003-1105-5

Yadavi, A., Modaress Sanavi, A., Zarghami, R. (2000): The effects of drought stress on oats species in Germination Step. In Articles Summary in 6th Session of Agriculture and Plants Improvement Congress Iran, Mazandaran University (pp. 235-236).

Zayed, M.A., Zeid, I.M. (1998): Effect of water and salt stress on growth, chlorophyll, mineral ions and organic solutes and enzymes activity in mung bean seedlings. Biologia Plantarum, 40: 351-356. https://doi.org/10.1023/A:1001057728794

Zhu, J., Kang, H., Tan, H., Xu, M. (2006): Effects of drought stresses induced by polyethylene glycol on germination of Pinus sylvestris var. mongolica seeds from natural and plantation forests on sandy land. Journal of Forest research, 11(5), 319-328. DOI 10.1007/s10310-006-0214-y 